\title{
Bone loss of vertebral bodies at the operative segment after cervical arthroplasty: a potential complication?
}

\author{
Dong Hwa Heo, MD, PhD, Dong Chan Lee, MD, Jong Yang Oh, MD, and \\ Choon Keun Park, MD, PhD \\ Department of Neurosurgery, Spine Center, The Leon Wiltse Memorial Hospital, Gyeonggi-do, Korea
}

\begin{abstract}
OBJECTIVE Bony overgrowth and spontaneous fusion are complications of cervical arthroplasty. In contrast, bone loss or bone remodeling of vertebral bodies at the operation segment after cervical arthroplasty has also been observed. The purpose of this study is to investigate a potential complication-bone loss of the anterior portion of the vertebral bodies at the surgically treated segment after cervical total disc replacement (TDR)—and discuss the clinical significance.
\end{abstract}

METHODS All enrolled patients underwent follow-up for more than 24 months after cervical arthroplasty using the Baguera $\mathrm{C}$ disc. Clinical evaluations included recording demographic data and measuring the visual analog scale and Neck Disability Index scores. Radiographic evaluations included measurements of the functional spinal unit's range of motion and changes such as bone loss and bone remodeling. The grading of the bone loss of the operative segment was classified as follows: Grade 1, disappearance of the anterior osteophyte or small minor bone loss; Grade 2, bone loss of the anterior portion of the vertebral bodies at the operation segment without exposure of the artificial disc; or Grade 3, significant bone loss with exposure of the anterior portion of the artificial disc.

RESULTS Forty-eight patients were enrolled in this study. Among them, bone loss developed in 29 patients (Grade 1 in 15 patients, Grade 2 in 6 patients, and Grade 3 in 8 patients). Grade 3 bone loss was significantly associated with postoperative neck pain $(p<0.05)$. Bone loss was related to the motion preservation effect of the operative segment after cervical arthroplasty in contrast to heterotopic ossification.

CONCLUSIONS Bone loss may be a potential complication of cervical TDR and affect early postoperative neck pain. However, it did not affect mid- to long-term clinical outcomes or prosthetic failure at the last follow-up. Also, this phenomenon may result in the motion preservation effect in the operative segment after cervical TDR.

https://thejns.org/doi/abs/10.3171/2016.10.FOCUS16393

KEY WORDS cervical vertebrae; neck pain; total disc replacement; bone remodeling; bone loss

$\mathrm{A}$ NTERIOR cervical discectomy and arthroplasty are treatment modalities for cervical radiculomyelopathy.,3,4,10,11,13,18 Many published articles have presented favorable clinical outcomes of anterior cervical discectomy and total disc replacement (TDR). . $7,10,18,20 \mathrm{We}^{2}$ have performed cervical arthroplasty in patients with cervical radiculomyelopathy due to cervical disc herniation. However, we experienced complications related to cervical arthroplasty such as postoperative segmental kyphosis, heterotopic ossification, osteolysis, dislocation of the prosthesis, bone-implant failure, and pullout of the artificial disc. $3,11,12,14,21$

Theoretically, cervical arthroplasty can preserve the motion of the surgically treated segment in contrast to cervical fusion surgeries. ${ }^{3,15,24}$ However, heterotopic ossification occurred in patients who underwent cervical TDR, and its effect interferes with motion preservation of the operative segments. ${ }^{11,14}$ Moreover, extensive heterotopic ossification led to the spontaneous fusion of the operative segments. ${ }^{11,14}$ Heterotopic ossification was one of the complications of cervical TDR..$^{11,14}$ In contrast, bone loss effect of the operative segments was reported in cases of cervical TDR treated with a Bryan artificial disc prosthesis (Medtronic Sofamor Danek). Bone loss of the superior adjacent vertebra of the operative segment-specifically around the anterior flange of the Bryan disc-developed. ${ }^{12}$

ABBREVIATIONS AP = anteroposterior; NDI = Neck Disability Index; ROM = range of motion; TDR = total disc replacement; VAS = visual analog scale. SUBMITTED September 5, 2016. ACCEPTED October 12, 2016. INCLUDE WHEN CITING DOI: 10.3171/2016.10.FOCUS16393. 

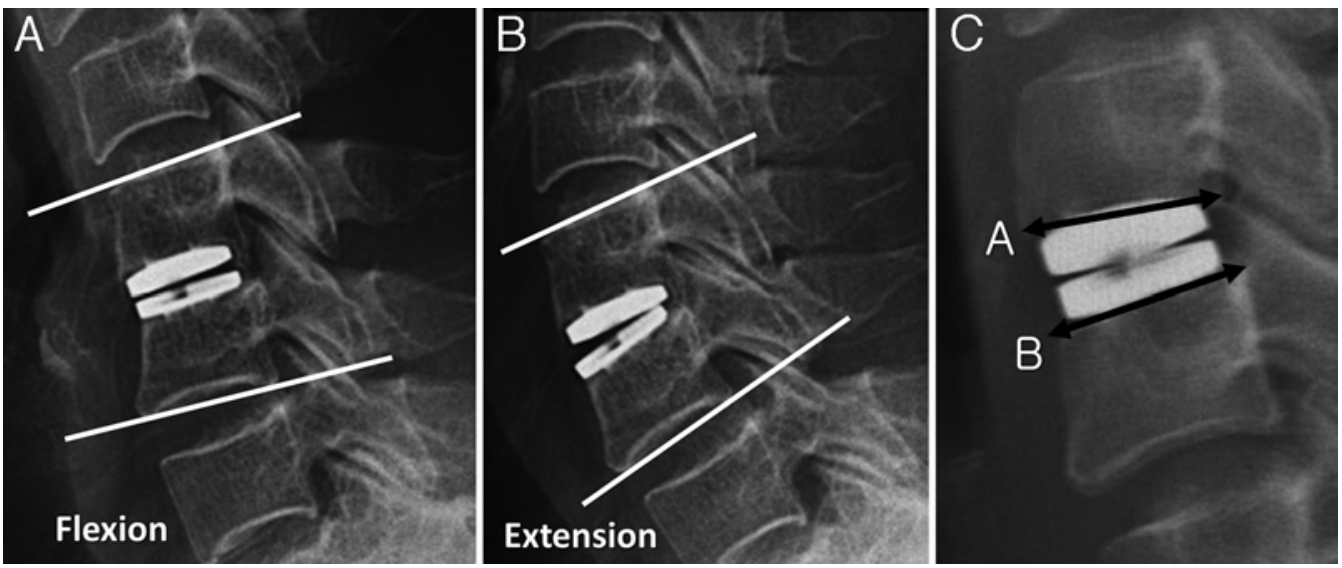

FIG. 1. A and B: The degree of ROM was calculated on the basis of the difference between extension and flexion. C: Measurement of the AP diameter of upper and lower endplates at the operative segments (diameter $=[A+B] / 2$ ).

We observed the loss of vertebral bodies at the operative segment after cervical arthroplasty using Baguera $C$ disc (Spineart), similar to the cases treated with the Bryan disc. $^{12}$

We could not determine whether bone loss or the bone remodeling effects around a cervical artificial disc prosthesis should be regarded solely as complications, and we did not exactly know the mechanism of bone loss. The purpose of this study is to investigate a potential complication-bone loss of the index segment after cervical TDR using Baguera $\mathrm{C}$-and discuss the clinical significance.

\section{Methods}

\section{Patient Population}

We retrospectively reviewed patients who underwent cervical arthroplasty with the use of Baguera $\mathrm{C}$ artificial discs (Spineart). A total of 78 patients have been treated with cervical TDR using Baguera $\mathrm{C}$ discs since October 2010. Cervical TDR was performed only in patients with soft-disc herniation from $\mathrm{C} 3-4$ to $\mathrm{C} 6-7$ that caused radiculomyelopathy. We did not perform cervical TDR in patients with instability, deformity, osteoporosis, ossification of the posterior longitudinal ligament, metabolic bone disease, or infection. We included only patients who underwent single-level cervical TDR and received follow-up for more than 24 months after cervical arthroplasty. Multilevel cervical arthroplasty or cervical hybrid operative cases were excluded from this study.

\section{Clinical and Radiological Parameters}

The clinical and radiological outcome data were collected at 1, 6, 12, and 24 months postoperatively and at the last follow-up. Clinical evaluations included recording demographic data, the visual analog scale (VAS) of the neck and arm, and the Neck Disability Index (NDI).

We acquired simple and dynamic radiographs (flexion/ extension) at 1, 6, 12, and 24 months and the final followup examination. Radiological changes such as heterotopic ossification and bone loss were evaluated. The range of motion (ROM) of each operative segment was evaluated using lateral flexion and extension radiographs. The ROM of the operative segments was calculated as the difference between extension and flexion (Fig. 1). The anteroposterior (AP) diameters of the lower endplate of the superior vertebral body and upper endplate of the inferior vertebral body were measured for evaluation of the progression of bone loss. The AP diameter was calculated on the basis of the mean value of the upper endplate of the inferior vertebral body and the lower endplate of the superior vertebral body (Fig. 1). We checked the serial changes in the AP diameters of the operation segments.

We classified the grading of bone loss of the operative segment as follows: Grade 1, disappearance of the anterior osteophyte or small minor bone loss; Grade 2, bone loss of the anterior portion of the vertebral bodies at the operation segment without exposure of the artificial disc; and Grade 3 , significant bone loss with exposure of the anterior portion of the artificial disc (Table 1 and Fig. 2).

We additionally divided the patients into 2 groups to evaluate bone loss. Patients with Grade 1 and 2 bone loss were assigned to the minor change group, and patients with Grade 3 bone loss were assigned to the major change group. We compared clinical outcomes (VAS of the neck and arm and NDI) between the minor and major change groups.

CT scans were obtained at 24 months postoperatively or the last follow-up. We evaluated the bone-to-implant interface and the morphological changes of the cortical

TABLE 1. Classification and grading system for bone loss after cervical arthroplasty

\begin{tabular}{cc}
\hline Grade & Definition \\
\hline 1 & $\begin{array}{c}\text { Disappearance of the anterior osteophyte or bone loss of } \\
\text { a small portion of the anterior margin of the vertebral } \\
\text { bodies of the operative segment. }\end{array}$ \\
\hline 2 & $\begin{array}{c}\text { Bone loss from the anterior portion of the vertebral body } \\
\text { to the anterior margin of the artificial disc. There was no } \\
\text { radiological exposure of the artificial disc. }\end{array}$ \\
\hline 3 & $\begin{array}{c}\text { The anterior portion of artificial disc prosthesis was } \\
\text { exposed due to bone loss. }\end{array}$ \\
\hline
\end{tabular}



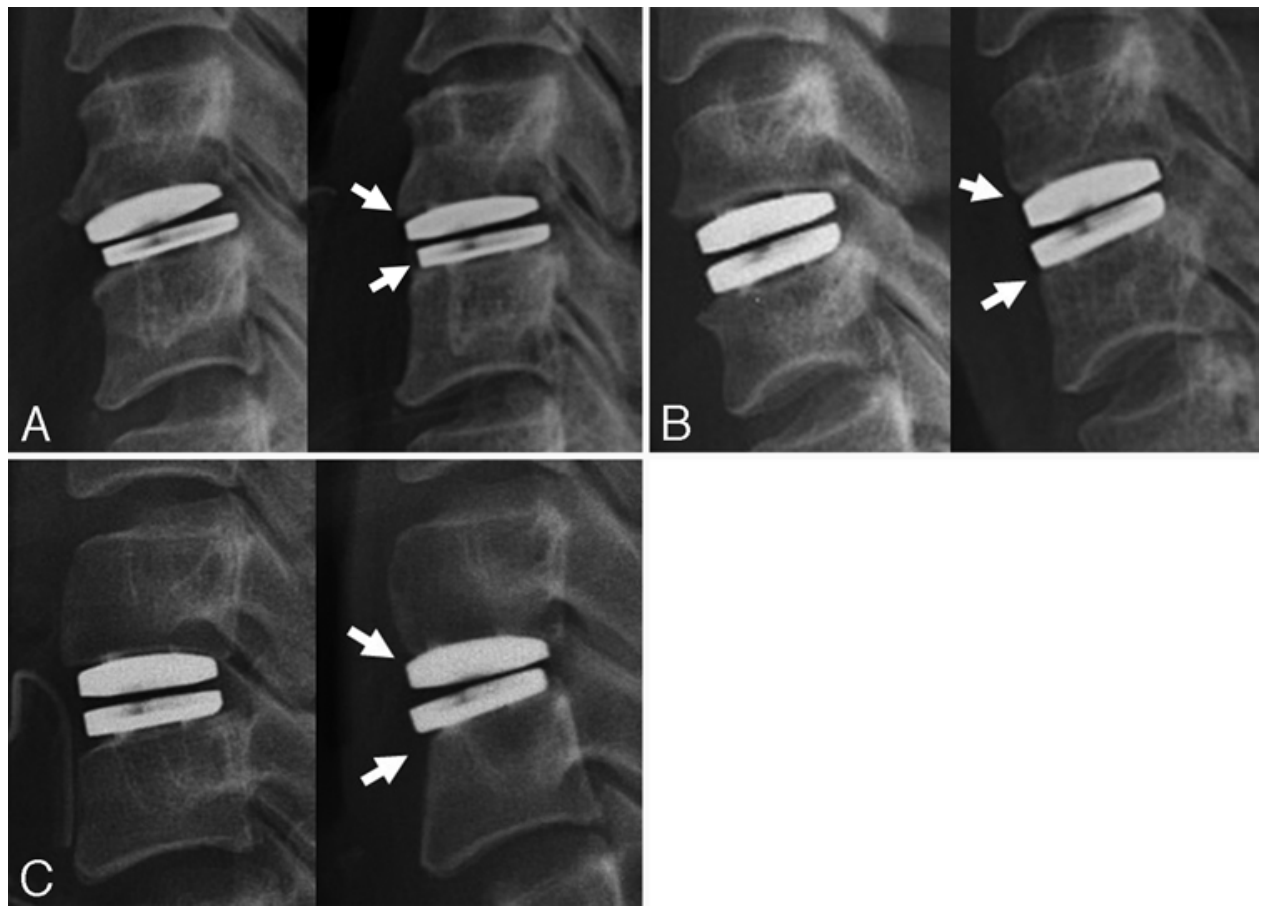

FIG. 2. Classification of bone loss after cervical arthroplasty. A: Grade 1. B: Grade 2. C: Grade 3 (see Table 1). Arrows indicate the bone loss area.

margin of the vertebral bodies at the operation segment using the postoperative CT images.

\section{Statistical Analysis}

Given the small sample size, we used nonparametric statistical analysis. The Mann-Whitney U-test and Wilcoxon signed-rank test were used for analysis; $p<0.05$ was considered to be statistically significant. We used $\mathrm{R}$ 3.1.2 for Windows for the statistical analysis.

\section{Results}

Among 78 patients, 48 patients were enrolled in this study. The 48 enrolled patients were treated by 5 different spine surgeons. The study group comprised 18 male and 30 female patients with a mean age of $50.1 \pm 7.4$ years. The mean follow-up period was $32.3 \pm 3.3$ months. The disc levels that were operated on ranged from C3-4 to C6-7: C3-4 in 1 patient; $\mathrm{C} 4-5$ in 6 patients; $\mathrm{C} 5-6$ in 33 patients; and $\mathrm{C} 6-7$ in 8 patients (Table 2).

Bone loss at the operative segments occurred in 29 (60.4\%) of 48 patients, and heterotopic ossification developed $14(29.2 \%)$ of 48 patients. Minor changes in bone loss occurred in 21 patients: Grade 1 in 15 patients, and Grade 2 in 6 patients. A major change (Grade 3) in bone loss occurred in 8 patients (Fig. 2). The mean AP diameter of the operative segments gradually decreased after the operation: $20.16 \pm 2.04 \mathrm{~mm}$ immediately postoperatively, $19.46 \pm 2.04 \mathrm{~mm}$ at 6 months postoperatively, $19.05 \pm 2.05$ $\mathrm{mm}$ at 12 months postoperatively, and $18.97 \pm 1.99 \mathrm{~mm}$ at $\geq 24$ months postoperatively. The mean AP diameter of the operative segments that was measured immediately after the operation significantly decreased in patients who experienced bone loss ( $p<0.05$; Fig. 3). Bone loss is also shown in Fig. 4.

The mean ROM of the operation segment was $9.1^{\circ} \pm$ $2.9^{\circ}$ preoperatively, and $11.4^{\circ} \pm 2.7^{\circ}$ at the final followup. The motion at the operative segment was maintained at the final follow-up in the 29 patients who experienced bone loss.

The cortical bone defect of the bone loss area and osteolytic lesion were not detected on the postoperative CT scans (Fig. 5).

Preoperative NDI significantly improved from $65.9 \pm$ 13.9 to $18.4 \pm 9.1$ at 24 months after surgery $(\mathrm{p}<0.05)$. The neck VAS score in the major change group (Grade 3

TABLE 2. Demographic data of patients

\begin{tabular}{lc}
\hline \multicolumn{1}{c}{ Characteristic } & Value \\
\hline Mean age \pm SD, yrs & $50.1 \pm 7.4$ \\
\hline Sex & 18 \\
\hline Male & 30 \\
\hline Female & $32.3 \pm 3.3$ \\
\hline Mean follow-up period \pm SD, mos & 1 \\
\hline Distribution of operative segments, no. of segments & 6 \\
\hline C3-4 & 8 \\
\hline C4-5 & $14(29.2)$ \\
\hline C6-7 & $29(60.4)$ \\
\hline Morphological changes at operative segments, no. (\%) \\
\hline Heterotopic ossification
\end{tabular}




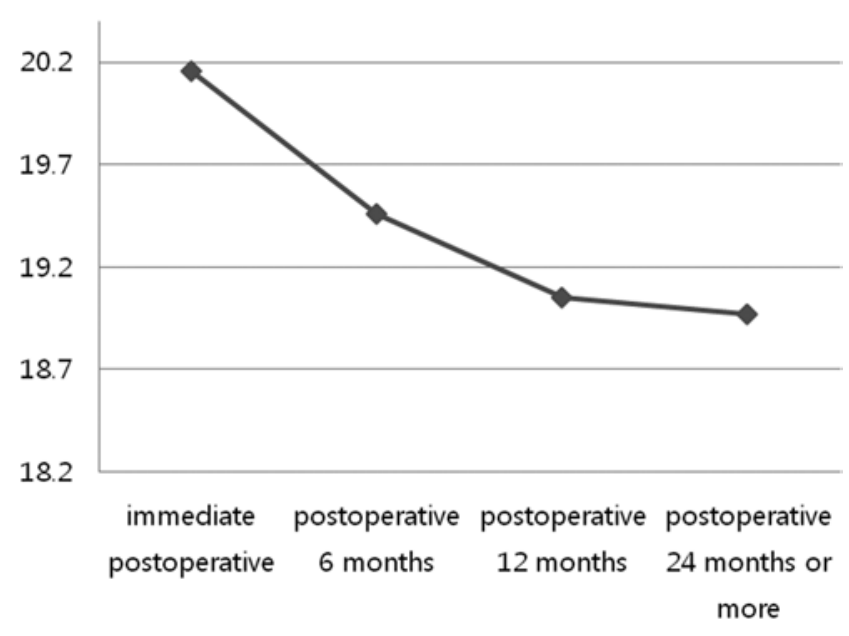

FIG. 3. Mean serial changes in the AP diameter (in mm, y-axis) of the operative segments after cervical arthroplasty using Baguera C.

bone loss) was significantly higher than that of the minor change group (Grade 1 and 2 bone loss) at 6 months and 12 months after cervical TDR (Table 3; $p<0.05$ ). There were no differences in the neck and arm VAS scores at the final follow-up ( $\geq 24$ months).

\section{Discussion}

Bone loss has been already presented in large joint replacements such as hip and knee joint arthroplasty. ${ }^{1,8,17,22}$ Bone loss has also developed around the joint prosthesis in patients who have undergone large joint replacement. The etiology of bone loss has not yet been determined. The possible mechanisms of bone loss after large joint replacement surgeries can be summarized as 1) a foreign body reaction of the implant with bone; 2) wear debris effect of the artificial prosthesis; 3) micromotion or micromovement effects at the bone-prosthesis interfaces; and 4) stress shielding effects. ${ }^{2,5,8,9}$ The mechanical causes of bone loss were the micromovement effects and stress shielding ef-

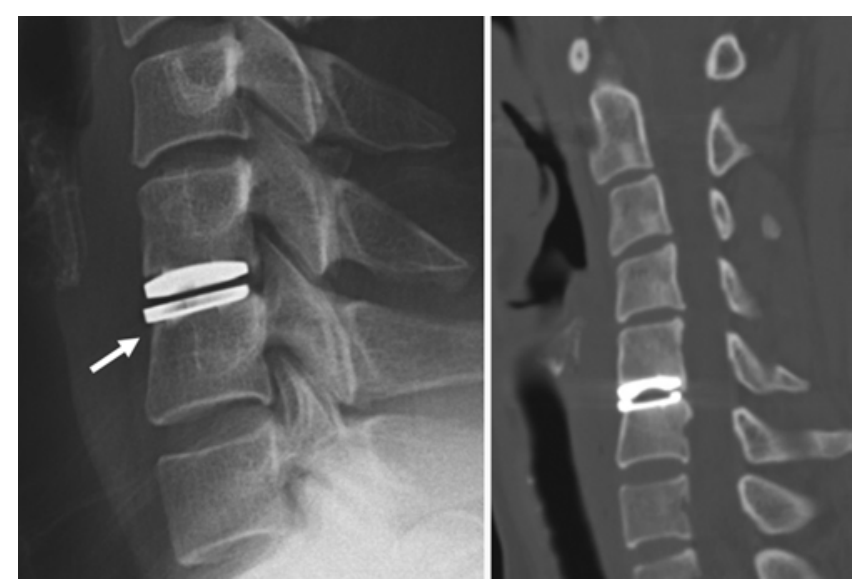

FIG. 5. A 36-year-old female patient received cervical TDR at C5-6. Although bone loss occurred at the operative segment (left, arrow), there was no osteolytic lesion or cortical bone defect around the bone loss area around the cervical artificial disc (right).

fects of the implants. The micromotion of the artificial joint into the bone may continuously induce mechanical damage to the bone around the prosthesis and subsequently bone loss occurs around the prosthesis..$^{12}$ The stress shielding effect is one of the factors of bone loss after arthroplasty. ${ }^{5,12}$ Femur bone loss and remodeling occur in the proximal portion of the femur after hip joint replacement surgery, and the stress shielding of the proximal femur may be a mechanical factor of bone loss. In contrast, the wear debris effect and foreign body reaction were biological inflammatory factors of the bone loss mechanism. Wear particles from the prosthesis are generated from the prosthesis and stimulate macrophages, foreign-body giant cells, and osteoclastic activity. ${ }^{16}$ Subsequently, bone loss or osteolysis around the artificial joint occurs. ${ }^{8}$

Bone loss around the Baguera $\mathrm{C}$ cervical disc prosthesis is different from bone loss due to joint arthroplasty. Postoperative CT images obtained over 2 years after cervical arthroplasty depicted that there was not osteolysis
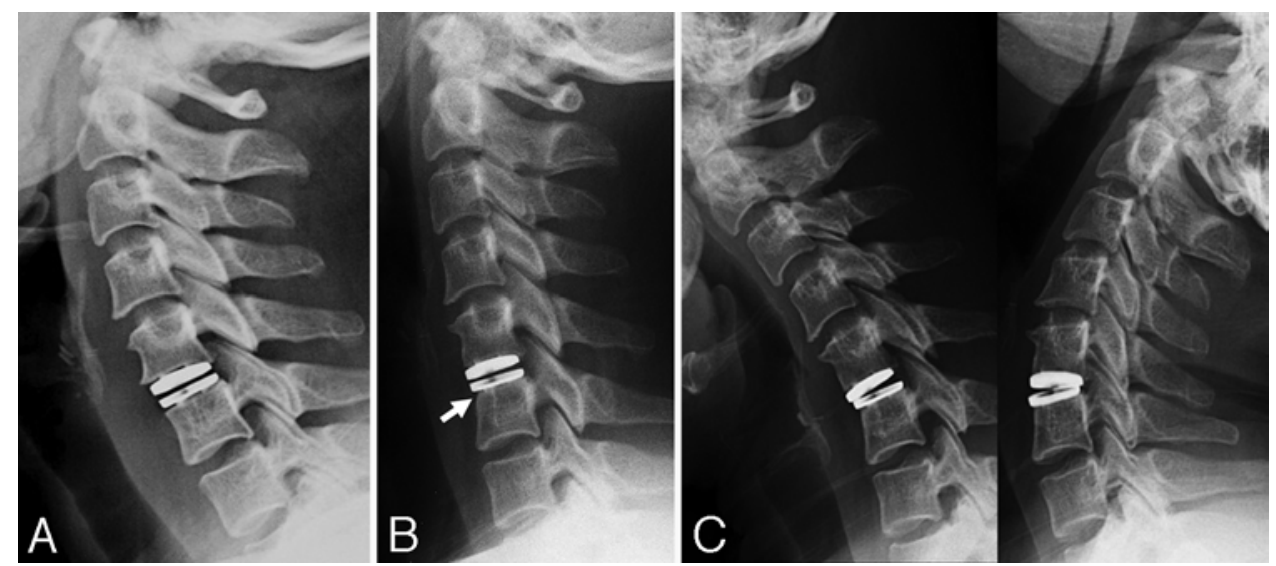

FIG. 4. Serial radiographs obtained in a 39-year-old female patient who was treated by undergoing cervical TDR at C5-6. A and B: Compared with the radiograph obtained immediately postoperatively (A), Grade 3 bone loss developed at the C5-6 area at 1 year after cervical TDR (B, arrow). C: The final postoperative follow-up lateral dynamic radiographs obtained 5 years after TDR revealed that the progression of bone loss had stopped and motion was still preserved. 
TABLE 3. Comparison of clinical outcomes between the minor and major change groups

\begin{tabular}{lcc}
\hline \multirow{2}{*}{ Outcome } & \multicolumn{2}{c}{ VAS Score $^{*}$} \\
\cline { 2 - 3 } & Minor Change Group & Major Change Group \\
\hline Arm & $9.0 \pm 0.09$ & $7.7 \pm 1.4$ \\
\hline Preop & $2.3 \pm 1.1$ & $2.1 \pm 0.8$ \\
\hline 6 mos postop & $2.1 \pm 1.0$ & $2.0 \pm 0.7$ \\
\hline 12 mos postop & $2.2 \pm 1.1$ & $2.0 \pm 1.2$ \\
\hline$\geq 24$ mos postop & & \\
\hline Neck & $4.7 \pm 3.1$ & $3.4 \pm 2.5$ \\
\hline Preop & $1.8 \pm 1.1$ & $5.3 \pm 2.0$ \\
\hline 6 mos postop $\dagger$ & $1.8 \pm 0.9$ & $4.7 \pm 1.7$ \\
\hline 12 mos postop $\dagger$ & $1.9 \pm 0.9$ & $2.1 \pm 1.4$ \\
\hline 224 mos postop &
\end{tabular}

* Values are shown as the mean $\pm \mathrm{SD}$.

$\dagger p<0.05$.

of the vertebrae but rather bone remodeling. The anterior vertebral cortical bone margin of the bone loss area was present; moreover, the artificial disc was well fused to the endplates of the vertebrae, and there was no radiolucent osteolytic lesion near the disc prosthesis. Therefore, the stress-shielding effect may be the main lesion of bone loss after cervical arthroplasty using Baguera $\mathrm{C}$ rather than the inflammatory osteolytic reaction. In the normal cervical spine, the instantaneous axis of rotation of the intervertebral motion segment changes with motion. However, cervical artificial discs may alter the physiological biomechanics and the instantaneous axis of rotation. ${ }^{6,19} \mathrm{We}$ suggest that these effects may be influenced by stressful mechanical change on the vertebral bodies after cervical TDR. Subsequently, bone loss developed in the vertebral body in cases of cervical TDR using Baguera C.

Osteolytic bone loss was previously reported in a case in which the patient underwent placement of the ProDiscC. ${ }^{21,23}$ The central keel of the ProDisc-C was penetrated and fixed to the vertebral body. The keel portion was directed toward contact with the bone marrow area. Osteolytic lesion formation occurred around the keel portion of the ProDisc-C. ${ }^{21}$ Wear debris particles and the foreign body reaction may affect osteolysis after cervical TDR using ProDisc-C. Moreover, bone loss after cervical TDR has been reported with the Bryan cervical artificial disc. ${ }^{12}$ The bone loss pattern in the Bryan disc was similar to our Baguera $\mathrm{C}$ cases. Kim et al. ${ }^{12}$ reported that the anterior flange of the Bryan artificial disc might result in wear debris and stress shield effects. These effects were causes of bone loss after Bryan disc arthroplasty. However, the Baguera $\mathrm{C}$ artificial disc does not have the anterior flange. We suggest that the biomechanical changes of cervical arthroplasty may be another factor of bone loss, and each specific property of the biomaterials of the cervical artificial discs may be associated with bone loss.

Fortunately, bone loss did not continuously progress in our study. Bone loss continued until approximately 1 year after cervical TDR, and then it stopped. Moreover, the motion of the operative segments was well preserved at 2 years or more after cervical arthroplasty. Heterotopic ossification after cervical TDR is related to motion restriction or spontaneous fusion at the operative level. Bone loss might be responsible for a good portion of the motion preservation of the operative segment compared with heterotopic ossification. A major change (Grade 3) in bone loss after cervical arthroplasty was associated with postoperative neck pain. Although some patients with Grade 3 bone loss complained of postoperative neck pain 1 year after cervical TDR, the postoperative neck pain spontaneously improved. Therefore, we cannot conclude if bone loss is a real complication or not.

Although we did not investigate physical activity, occupation, and socioeconomic status, the majority of the patients in the major bone loss group (Grade 3) may have had a high level of physical or occupational activity. We suggest that physical activity might be associated with bone loss. A further larger study about cervical arthroplasty must include factors of occupational and physical activities.

The limitation of this study is the small sample size. Moreover, we analyzed only Baguera $\mathrm{C}$ case series. Further studies should include a larger number of cases and various types of cervical artificial discs for the evaluation of the clinical importance of bone loss.

\section{Conclusions}

Bone loss may be a potential complication related to cervical TDR using Baguera $\mathrm{C}$ and associated with early postoperative neck pain. However, bone loss did not affect the mid- to long-term clinical outcomes or increase the rates of bone-to-prosthesis failure at the last follow-up. Also, this phenomenon may result in the motion preservation effect of the operation segment after cervical TDR. We cannot conclude whether bone loss is a true complication or not. A long-term follow-up and large-population study should be undertaken to evaluate the long-term effects of bone loss.

\section{References}

1. Au AG, James Raso V, Liggins AB, Amirfazli A: Contribution of loading conditions and material properties to stress shielding near the tibial component of total knee replacements. J Biomech 40:1410-1416, 2007

2. Boyle C, Kim IY: Comparison of different hip prosthesis shapes considering micro-level bone remodeling and stressshielding criteria using three-dimensional design space topology optimization. J Biomech 44:1722-1728, 2011

3. Burkus JK, Traynelis VC, Haid RW Jr, Mummaneni PV: Clinical and radiographic analysis of an artificial cervical disc: 7-year follow-up from the Prestige prospective randomized controlled clinical trial: Clinical article. J Neurosurg Spine 21:516-528, 2014

4. Carrier CS, Bono CM, Lebl DR: Evidence-based analysis of adjacent segment degeneration and disease after ACDF: a systematic review. Spine J 13:1370-1378, 2013

5. Chen CM, Tsai WC, Lin SC, Tseng CS: Effects of stemmed and nonstemmed hip replacement on stress distribution of proximal femur and implant. BMC Musculoskelet Disord 15:312, 2014

6. Colle KO, Butler JB, Reyes PM, Newcomb AG, Theodore N, Crawford NR: Biomechanical evaluation of a metal-on-metal 
cervical intervertebral disc prosthesis. Spine J 13:16401649,2013

7. Coric D, Kim PK, Clemente JD, Boltes MO, Nussbaum M, James S: Prospective randomized study of cervical arthroplasty and anterior cervical discectomy and fusion with long-term follow-up: results in 74 patients from a single site. J Neurosurg Spine 18:36-42, 2013

8. Fraser JF, Werner S, Jacofsky DJ: Wear and loosening in total knee arthroplasty: a quick review. J Knee Surg 28:139-144, 2015

9. Gallo J, Goodman SB, Konttinen YT, Wimmer MA, Holinka M: Osteolysis around total knee arthroplasty: a review of pathogenetic mechanisms. Acta Biomater 9:8046-8058, 2013

10. Heller JG, Sasso RC, Papadopoulos SM, Anderson PA, Fessler RG, Hacker RJ, et al: Comparison of BRYAN cervical disc arthroplasty with anterior cervical decompression and fusion: clinical and radiographic results of a randomized, controlled, clinical trial. Spine (Phila Pa 1976) 34:101-107, 2009

11. Kim KS, Heo DH: Do postoperative biomechanical changes induce heterotopic ossification after cervical arthroplasty? A 5-year follow-up study. Clin Spine Surg 29:E309-E313, 2016

12. Kim SH, Chung YS, Ropper AE, Min KH, Ahn TK, Won $\mathrm{KS}$, et al: Bone loss of the superior adjacent vertebral body immediately posterior to the anterior flange of Bryan cervical disc. Eur Spine J 24:2872-2879, 2015

13. Lin EL, Wang JC: Total disk arthroplasty. J Am Acad Orthop Surg 14:705-714, 2006

14. Meisel HJ, Jurák L, Antinheimo J, Arregui R, Bruchmann $\mathrm{B}$, Čabraja M, et al: Four-year results of a prospective singlearm study on 200 semi-constrained total cervical disc prostheses: clinical and radiographic outcome. J Neurosurg Spine 25:556-565, 2016

15. Mummaneni PV, Amin BY, Wu JC, Brodt ED, Dettori JR, Sasso RC: Cervical artificial disc replacement versus fusion in the cervical spine: a systematic review comparing longterm follow-up results from two FDA trials. Evid Based Spine Care J 3 (S1):59-66, 2012

16. Orishimo KF, Claus AM, Sychterz CJ, Engh CA: Relationship between polyethylene wear and osteolysis in hips with a second-generation porous-coated cementless cup after seven years of follow-up. J Bone Joint Surg Am 85-A:1095-1099, 2003

17. Panegrossi G, Ceretti M, Papalia M, Casella F, Favetti F, Falez F: Bone loss management in total knee revision surgery. Int Orthop 38:419-427, 2014

18. Radcliff K, Coric D, Albert T: Five-year clinical results of cervical total disc replacement compared with anterior discectomy and fusion for treatment of 2-level symptomatic degenerative disc disease: a prospective, randomized, controlled, multicenter investigational device exemption clinical trial. J Neurosurg Spine 25:213-224, 2016

19. Safavi-Abbasi S, Reyes PM, Abjornson C, Crawford NR: Feasibility and biomechanics of multilevel arthroplasty and combined cervical arthrodesis and arthroplasty. Clin Spine Surg 29:E522-E531, 2016

20. Traynelis VC, Arnold PM, Fourney DR, Bransford RJ, Fischer DJ, Skelly AC: Alternative procedures for the treatment of cervical spondylotic myelopathy: arthroplasty, oblique corpectomy, skip laminectomy: evaluation of comparative effectiveness and safety. Spine (Phila Pa 1976) [epub ahead of print], 2013

21. Tumialán LM, Gluf WM: Progressive vertebral body osteolysis after cervical disc arthroplasty. Spine (Phila Pa 1976) 36:E973-E978, 2011

22. Vasso M, Beaufils P, Cerciello S, Schiavone Panni A: Bone loss following knee arthroplasty: potential treatment options. Arch Orthop Trauma Surg 134:543-553, 2014

23. Veruva SY, Lanman TH, Hanzlik JA, Kurtz SM, Steinbeck MJ: Rare complications of osteolysis and periprosthetic tissue reactions after hybrid and non-hybrid total disc replacement. Eur Spine J 24 (Suppl 4):S494-S501, 2015

24. Wu JC, Hsieh PC, Mummaneni PV, Wang MY: Spinal motion preservation surgery. BioMed Res Int 2015:372502, 2015

\section{Disclosures}

The authors report no conflict of interest concerning the materials or methods used in this study or the findings specified in this paper.

\section{Author Contributions}

Conception and design: all authors. Acquisition of data: Heo, Oh. Analysis and interpretation of data: Heo. Drafting the article: Heo. Critically revising the article: Heo. Reviewed submitted version of manuscript: Park, Heo, Lee. Approved the final version of the manuscript on behalf of all authors: Park. Statistical analysis: Heo. Administrative/technical/material support: Heo.

\section{Correspondence}

Choon Keun Park, Department of Neurosurgery, The Leon Wiltse Memorial Hospital, 994-3, Ingye-dong, Paldal-gu, Suwon-si, Gyeonggi-do 442-833, Korea. email: allspine@gmail.com. 